\title{
Maternal and perinatal outcome in heart disease complicating pregnancy
}

\author{
Tanvi Kumar ${ }^{1 *}$, Rishman Tandi², Amritaa Thalla ${ }^{3}$
}

\author{
${ }^{1}$ Department of Obstetrics and Gynaecology, Saraswati Mission Hospital, Kurukshetra, Haryana, India \\ ${ }^{2}$ Department of Internal Medicine, Saraswati Mission Hospital, Kurukshetra, Haryana, India \\ ${ }^{3}$ Maheshwara Medical College, Hyderabad, Telangana, India
}

Received: 05 September 2021

Revised: 17 September 2021

Accepted: 18 September 2021

\author{
*Correspondence: \\ Dr. Tanvi Kumar, \\ E-mail: tanvinangru3108@gmail.com
}

Copyright: (C) the author(s), publisher and licensee Medip Academy. This is an open-access article distributed under the terms of the Creative Commons Attribution Non-Commercial License, which permits unrestricted non-commercial use, distribution, and reproduction in any medium, provided the original work is properly cited.

\section{ABSTRACT}

Background: Congenital as well as acquired heart diseases remain one of the important factors complicating pregnancy and remains a significant cause of maternal as well as perinatal morbidity and mortality. Pregnant women with cardiac diseases need a comprehensive management strategy to minimize the adverse effect of cardiac conditions on pregnancy and its outcome.

Methods: This was an observational study conducted in a tertiary care hospital located in an urban area. Pregnant patients diagnosed to be having congenital or acquired heart diseases and admitted either in ward, labour room or intensive care unit were included in this study on the basis of a predefined inclusion and exclusion criteria. Detailed history was taken and clinical examination was done in all the cases. Patients were classified according to New York Heart Association. Maternal and perinatal Outcome was studied in cases.

Results: The incidence of cardiac disease amongst pregnant patients during study period was found to be $0.58 \%$. The mean age of studied cases was found to be $23.16 \pm 5.06$ years. Most of the patients were primigravida $(85.71 \%)$ and 6 patients $(14.29 \%)$ were multigravida. The majority of the patients $(76.19 \%)$ belonged to NYHA grade I whereas 8 $(19.05 \%)$ patients belonged to NYHA class II. 1 patient belonged to NYHA Class III and Class IV respectively. Isolated mitral stenosis secondary to rheumatic valvular involvement was the single most common lesion seen in studied cases and was seen in $8(19.05 \%)$ patients. Ventricular septal defect was most common congenital heart disease (14.28\%). 26 $(61.90 \%)$ delivered by normal vaginal delivery whereas emergency and elective LSCS was done in $9(21.43 \%)$ and 6 $(14.29 \%)$ patients respectively. nature of cardiac disease was common factor for elective cesarean section which was done in 5 cases $(11.90 \%)$. Postpartum cardiac failure $(14.29 \%)$ and postpartum hemorrhage $(9.52 \%)$ were common maternal complications. $24(57.14 \%)$ neonates required admission in neonatal intensive care unit. The most common indication for NICU admission was found to be low birth weight $(23.81 \%)$ followed by birth asphyxia (19.05\%).

Conclusions: Cardiac disease in pregnancy is associated with increased risk of maternal as well as perinatal morbidity and mortality. Early diagnosis and management during pregnancy is essential to reduce maternal as well as perinatal outcome in these cases.

Keywords: Pregnancy, Congenital heart disease, Rheumatic heart disease, Maternal and perinatal outcome

\section{INTRODUCTION}

Congenital as well as acquired heart diseases remain one of the important factors complicating pregnancy. ${ }^{1}$ With advances in maternal care there is not only a considerable decline in maternal deaths but also there is an overall improvement in fetal outcome in patients having cardiac diseases. Despite reduction in maternal mortality cardiac 
diseases complicating pregnancy remain one of the significant causes of maternal morbidity as well as mortality particularly in developing countries. $^{2}$ Hemodynamic changes taking place during pregnancy are generally well tolerated in healthy women but in cases where there is a pre-existing congenital or acquired heart disease there is a considerable risk of maternal as well as fetal morbidity and in cases of complex congenital heart diseases there is significant risk of maternal mortality. ${ }^{3}$ Unrecognized heart diseases remain one of the biggest concerns faced by obstetricians in developing world. In considerable number of women, the heart disease remains unrecognized only to be diagnosed during later stages of pregnancy. $^{4}$

In past women with cardiac diseases were discouraged from conceiving, but with significant advances in comprehensive cardiac as well as obstetric care has made it possible for women with cardiac conditions to conceive except in cases such as severe fixed valvular stenosis, hypertrophic obstructive cardiomyopathy or severe congestive cardiac failure where pregnancy still remains contraindicated. Unlike in the Western world rheumatic valvular heart diseases commonly complicates pregnancy in developing countries including India and remains one of the important causes of maternal as well as fetal morbidity and mortality. 5

One of the important factors which needs to be considered because of improvements and advances in medicine is that with improvements in medical care and facilities there are a significant improvement in survival of patients with congenital heart diseases and their life expectancy has improved considerably leading to increase incidence of pregnancy complicated by heart diseases. This is more so in developed world. ${ }^{6}$

One of the important considerations of managing these patients is that there are many medications which can be given a non-pregnant patient may be contraindicated during pregnancy because of their known teratogenic or adverse effect on fetus. ${ }^{7}$ In this regard a careful decision has to be taken by treating physician as well as obstetrician so as to effectively treat the cardiac condition while taking utmost care to minimize the effects of drugs on growing fetus. Another important consideration while managing pregnancy complicated by cardiac disease include the adverse effect these conditions have on fetal outcome. ${ }^{8}$ Pregnancies complicated by cardiac diseases are known to increase the incidence of preterm births with consequent increase in complications such as hyaline membrane disease, neonatal hyperbilirubinemia, necrotizing enterocolitis and intracranial hemorrhage. Symmetric as well as asymmetric intrauterine growth restriction is also common in pregnancies complicated by cardiac diseases. The management of these patients require a comprehensive approach that involves physicians, cardiologists as well as obstetrician. Each cardiac condition pose different risk and management strategy which needs to be individualized taking into consideration the severity of the cardiac disease. ${ }^{9}$

We conducted this observational study to analyze maternal and perinatal outcome in pregnancies complicated by cardiac diseases.

\section{METHODS}

This was an observational study conducted in Saraswati Mission Hospital, Kurukshetra, Haryana. The duration of study was February 2019 to July 2020. Pregnant patients diagnosed to be having congenital or acquired heart diseases and admitted either in ward, labour room or intensive care unit and who delivered after 28 completed weeks of gestation were included in this study. Patients having serious comorbid conditions and mothers of syndromic babies were excluded from the study. Informed written consent was obtained from all the patients. On first antenatal visit a detailed history with respect to maternal age, parity, weeks of gestation, type of cardiac disease and duration since diagnosis was noted down. Relevant family history and history of any systemic illness such as hypertension or diabetes was also noted. A through general and systemic examination was done in all the cases.

\section{Table 1: New York Heart Association functional classification.}

\begin{tabular}{|c|c|}
\hline NYHA class & Symptoms \\
\hline $\mathbf{I}$ & $\begin{array}{l}\text { No limitation of physical activity. } \\
\text { Ordinary physical activity does not } \\
\text { cause undue fatigue, palpitation, } \\
\text { dyspnea (shortness of breath). }\end{array}$ \\
\hline II & $\begin{array}{l}\text { Slight limitation of physical activity. } \\
\text { Comfortable at rest. Ordinary physical } \\
\text { activity results in fatigue, palpitation, } \\
\text { dyspnea (shortness of breath). }\end{array}$ \\
\hline III & $\begin{array}{l}\text { Marked limitation of physical activity. } \\
\text { Comfortable at rest. Less than } \\
\text { ordinary activity causes fatigue, } \\
\text { palpitation, or dyspnea. }\end{array}$ \\
\hline IV & $\begin{array}{l}\text { Unable to carry on any physical } \\
\text { activity without discomfort. } \\
\text { Symptoms of heart failure at rest. If } \\
\text { any physical activity is undertaken, } \\
\text { discomfort increases. }\end{array}$ \\
\hline
\end{tabular}

Basic investigations including complete blood count, random blood sugar levels, routine urine examination and obstetric ultrasound examination was done on 1st antenatal visit. ECG and 2 D Echocardiography was done in all cases to determine type and severity of cardiac disease. Patients were classified as per New York Heart Association (NYHA) which divides the patients amongst 4 classes depending upon symptoms a patient experiences during routine and daily activities. 
Depending upon the type of cardiac disease patients were divided into those having congenital and those having acquired cardiac diseases. Antenatal follow up visits protocol was decided depending upon the severity and type of cardiac disease as well as the stage of pregnancy. At each antenatal visit patients were evaluated to assess improvement or deterioration of cardiac status.

Patients were evaluated for obstetric outcome such as incidence of precipitate labour, premature delivery, Type of delivery (Normal, instrumental or cesarean section), incidence of antepartum or postpartum hemorrhage. Maternal morbidity and mortality were also recorded amongst studied cases. The effect of pregnancy on functional status of women as shown according to NYHA classification was determined by antenatal and postnatal evaluation of patients for severity of disease as per NYHA criteria. Incidence of complications such as congestive cardiac failure, pulmonary edema, infective endocarditis and arrhythmias was also analyzed. Perinatal outcome was assessed in terms of incidence of preterm birth (less than 37 weeks of completed gestation), incidence of low birth weight $(<2.5 \mathrm{~kg})$, very low birth weight $(<1.5 \mathrm{~kg})$ and extremely low birth weight $(<1 \mathrm{~kg})$ babies.

Patients were discharged 1 week after delivery if no complications were present. Patients were advised about contraception or permanent sterilization (either of patient or her husband) depending upon type and severity of cardiac illness.

Statistical analysis was done using SSPS 21.0 software and $\mathrm{p}$ value less than 0.05 was taken as statistically significant.

\section{RESULTS}

During the study period a total of 7212 deliveries took place. Out of these patients 42 patients were found to have cardiac diseases either congenital or acquired, hence the incidence of cardiac disease amongst pregnant patients during study period was found to be $0.58 \%$.

Table 2: Type of cardiac diseases in studied cases.

\begin{tabular}{|lll|}
\hline Cardiac disease & $\begin{array}{l}\text { No. of } \\
\text { patients }\end{array}$ & Percentage \\
\hline Congenital heart diseases & 12 & 28.57 \\
\hline Rheumatic heart disease & 24 & 57.14 \\
\hline Cardiomyopathy & 4 & 9.52 \\
\hline Arrythmias & 2 & 4.76 \\
\hline Total & 42 & 100 \\
\hline
\end{tabular}

Rheumatic heart disease was the most common cardiac pathology complicating pregnancy and was seen in 24 $(57.14 \%)$ patients whereas congenital heart disease was seen in $12(28.57 \%)$ patients. Cardiomyopathy and arrythmias were seen in $4(9.52 \%)$ and $2(4.76 \%)$ respectively.
Table 3: Age groups of the studied cases.

\begin{tabular}{|lll|}
\hline $\begin{array}{l}\text { Age groups } \\
\text { (in years) }\end{array}$ & No. of patients & Percentage \\
\hline $\mathbf{1 8 - 2 5}$ & 28 & 66.67 \\
\hline $\mathbf{2 6 - 3 0}$ & 10 & 23.81 \\
\hline $\mathbf{3 1 - 3 5}$ & 3 & 7.14 \\
\hline$>\mathbf{3 5}$ & 1 & 2.38 \\
\hline Total & 42 & 100.00 \\
\hline Mean age \pm SD $=$ & $23.16 \pm 5.06$ years \\
\hline
\end{tabular}

Table 4: Primigravida versus multigravida in studied cases.

\begin{tabular}{|l|l|l|}
\hline Gravida & \multicolumn{2}{|l|}{$\begin{array}{l}\text { Pregnancies with cardiac } \\
\text { conditions }\end{array}$} \\
\hline No. of cases & Percentage \\
\hline Primigravida & 36 & 85.71 \\
\hline Multigravida & 6 & 14.29 \\
\hline Total & 42 & 100 \\
\hline
\end{tabular}

Table 5: New York Heart Association classification of studied cases.

\begin{tabular}{|l|l|l|}
\hline $\begin{array}{l}\text { Mode of } \\
\text { delivery }\end{array}$ & No. of cases & Percentage \\
\hline NYHA I & 32 & 76.19 \\
\hline NYHA II & 8 & 19.05 \\
\hline NYHA III & 1 & 2.38 \\
\hline NYHA IV & 1 & 2.38 \\
\hline Total & 42 & 100.00 \\
\hline
\end{tabular}

The age group of the studied cases showed that out of 42 cases the most common age group was found to be $18-25$ years $(66.67 \%)$ followed by $26-30$ years $(23.81 \%)$ and 31 $35(7.14 \%)$ years of age. Only 1 patient was above age of 35 years $(2.38 \%)$.

Amongst the studied cases most of the patients were primigravida $(85.71 \%)$ and 6 patients (14.29\%) were multigravida. Out of 6 patients who were multigravida 5 patients were unaware of cardiac conditions while remaining 1 patient was a diagnosed case of small atrial septal defect.

The distribution of the patients on the basis of Modified Kuppuswamy scale showed that in studied cases majority of the patients (47.62\%) belonged to lower middle class followed by middle class $(38.10 \%)$ and lower class $(9.52 \%)$. No patient belonged to upper class.

The analysis of the cases on the basis New York heart Association showed that majority of the patients (76.19\%) belonged to NYHA grade I whereas $8(19.05 \%)$ patients belonged to NYHA class II. 1 patient belonged to NYHA Class III and Class IV respectively. 
Table 6: Types of cardiac diseases in studied cases.

\begin{tabular}{|c|c|c|c|}
\hline \multirow{2}{*}{ Type } & \multirow{2}{*}{ Lesion } & \multicolumn{2}{|l|}{ Cases } \\
\hline & & Number & Percentage \\
\hline \multirow{5}{*}{$\begin{array}{l}\text { Congenital heart } \\
\text { disease }\end{array}$} & Atrial septal defect without pulmonary arterial hypertension & 3 & 7.14 \\
\hline & Atrial septal defect with pulmonary arterial hypertension & 2 & 4.76 \\
\hline & Small VSD without pulmonary arterial hypertension & 5 & 11.90 \\
\hline & VSD with pulmonary arterial hypertension & 1 & 2.38 \\
\hline & Patent ductus arteriosus without pulmonary arterial hypertension & 1 & 2.38 \\
\hline \multirow{4}{*}{$\begin{array}{l}\text { Rheumatic } \\
\text { valvular heart } \\
\text { disease }\end{array}$} & Isolated mitral stenosis & 8 & 19.05 \\
\hline & Isolated mitral regurgitation & 6 & 14.29 \\
\hline & Isolated aortic regurgitation & 1 & 2.38 \\
\hline & Mixed valvular lesions & 9 & 21.43 \\
\hline Cardiomyopathy & Peripartum cardiomyopathy & 4 & 9.52 \\
\hline Arrythmias & Supraventricular tachycardia & 2 & 4.76 \\
\hline
\end{tabular}

The analysis of the cases on the basis of cardiac diseases showed that isolated mitral stenosis secondary to rheumatic valvular involvement was the single most common lesion seen in studied cases and was seen in 8 $(19.05 \%)$ patients. The other common valvular lesion was found to be isolated mitral regurgitation which was seen in $6(14.29 \%)$ patients. Mixed valvular lesions were seen in $9(21.43 \%)$ cases. The most common congenital heart disease was found to be small ventricular septal defect with no Pulmonary arterial Hypertension which was seen in 5 $(11.90 \%)$ patients. Peripartum cardiomyopathy and supraventricular tachyarrhythmias were seen in $4(9.52 \%)$ and $2(4.76 \%)$ patients respectively.

The analysis of studied cases on the basis of mode of delivery showed that in studied cases 26 (61.90\%) delivered by normal vaginal delivery whereas emergency and elective LSCS was done in $9(21.43 \%)$ and $6(14.29 \%)$ patients respectively. In 1 patient $(2.38 \%)$ instrumental delivery was done.

Table 7: Type of delivery in studied cases.

\begin{tabular}{|lll|}
\hline Mode of delivery & $\begin{array}{l}\text { No. of } \\
\text { cases }\end{array}$ & Percentage \\
\hline Normal delivery & 26 & 61.90 \\
\hline Elective LSCS & 7 & 14.29 \\
\hline Emergency LSCS & 8 & 21.43 \\
\hline $\begin{array}{l}\text { Forceps/vacuum } \\
\text { delivery }\end{array}$ & 1 & 2.38 \\
\hline Total & 42 & 100.00 \\
\hline
\end{tabular}

The analysis of need for cesarean section in studied cases showed that nature of cardiac disease was common factor for elective cesarean section which was done in 5 cases
(11.90\%) LSCS for fetal distress. Transverse lie and cephalopelvic disproportion were the other causes for elective cesarean section in studied cases. The other causes of LSCS included Fetal distress (7.14\%), pre-eclampsia $(2.38 \%)$, failed induction $(2.38 \%)$ and non-progression of labor $(2.38 \%)$.

There was no maternal mortality in any of the studied cases. $4(9.52 \%)$ patients developed postpartum hemorrhage. Amongst remaining patients 7 (14.29\%) patients required oxygen supplementation in immediate postoperative period which however was successfully tapered off within 24 hours.

Table 8: Indications for LSCS in studied cases.

\begin{tabular}{|lll|}
\hline Indication for LSCS & $\begin{array}{l}\text { No. of } \\
\text { patients }\end{array}$ & Percentage \\
\hline Failed induction & 1 & 2.38 \\
\hline $\begin{array}{l}\text { Non-Progress of } \\
\text { labour }\end{array}$ & 1 & 2.38 \\
\hline Fetal Distress & 3 & 7.14 \\
\hline $\begin{array}{l}\text { Maternal } \\
\text { distress/nature of } \\
\text { cardiac disease }\end{array}$ & 5 & 11.90 \\
\hline $\begin{array}{l}\text { Cephalopelvic } \\
\text { disproportion }\end{array}$ & 1 & 2.38 \\
\hline Breech presentation & 1 & 2.38 \\
\hline Transverse lie & 1 & 2.38 \\
\hline PROM & 1 & 2.38 \\
\hline Severe pre-eclampsia & 1 & 2.38 \\
\hline Total & 15 & 35.71 \\
\hline
\end{tabular}

Table 9: Neonatal outcome in studied cases.

\begin{tabular}{|llll|}
\hline Neonatal outcome & & No. of patients & \multicolumn{1}{c|}{ Percentage } \\
\hline \multirow{3}{*}{ Birth weight of neonates } & Normal birth weight $(\geq 2.5 \mathrm{~kg})$ & 16 & 38.10 \\
\cline { 2 - 4 } & Low birth weight $(1.51-2.5 \mathrm{~kg})$ & 20 & 47.62 \\
\cline { 2 - 4 } & Very low birth weight $(1-1.5 \mathrm{~kg})$ & 5 & 11.90 \\
\cline { 2 - 3 } & Extremely low birth weight $(<1 \mathrm{Kg})$ & 1 & 2.38 \\
\hline
\end{tabular}

Continued 


\begin{tabular}{|llll|}
\hline Neonatal outcome & & No. of patients & Percentage \\
\hline & Total & 42 & 100.00 \\
\hline \multirow{4}{*}{ APGAR score at birth } & $<6$ & 8 & 19.05 \\
\cline { 2 - 4 } & $\geq 6$ & 34 & 80.95 \\
\cline { 2 - 4 } & Total & 42 & 100 \\
\hline \multirow{4}{*}{$\begin{array}{l}\text { Indications for NICU } \\
\text { admission }\end{array}$} & Asphyxia & 8 & 19.05 \\
\cline { 2 - 4 } & Preterm/Low birth weight care & 10 & 23.81 \\
\cline { 2 - 4 } & Respiratory distress & 3 & 7.14 \\
\cline { 2 - 4 } & Transient tachypnea of newborn & 3 & 7.14 \\
\cline { 2 - 4 } & Total & 24 & 57.14 \\
\hline
\end{tabular}

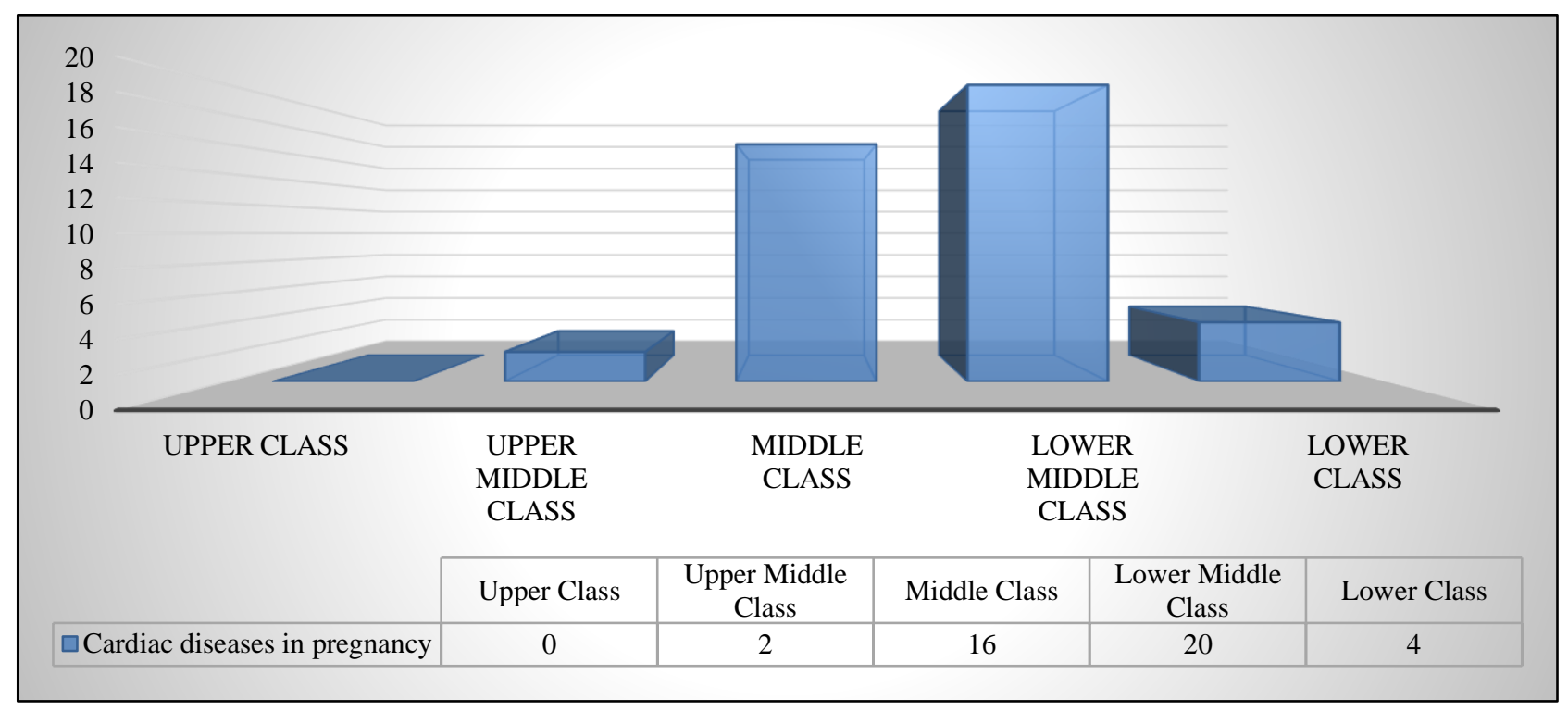

Figure 1: Socioeconomic status of studied cases.

The analysis of cases on the basis of neonatal outcome showed that out of 42 cases $16(38.10 \%)$ patients had a normal birth weight whereas low birth weight and very low birth weight babies were seen in $20(47.62 \%)$ and 5 $(11.90 \%)$ cases. 1 neonate was extremely low birth weight $(2.38 \%)$.

APGAR scores of all the neonates were recorded. APGAR score less than 6 was taken as suggestive of birth asphyxia. Amongst neonates 8 newborns had an APGAR score of less than 6 at 1 minute suggestive of birth asphyxia whereas in remaining $34(80.95 \%)$ neonates APGAR score at 1 minute was more than 6 .

The analysis of need for newborn babies' admission to NICU showed that $24(57.14 \%)$ neonates required admission in neonatal intensive care unit. The most common indication for NICU admission was found to be low birth weight $(23.81 \%)$ followed by birth asphyxia $(19.05 \%)$. Transient tachypnea of newborn and respiratory distress was cause of NICU admissions in $3(7.14 \%)$ patients each.

There was $1(2.38 \%)$ case of neonatal mortality in which the baby was born at 31 weeks of gestation and birth weight was 980 grams (extremely low birth weight). The baby was admitted in NICU for respiratory distress secondary to hyaline membrane disease and eventually developed respiratory failure on D2 of life.

\section{DISCUSSION}

Cardiac disease in pregnant patients is an important risk factor for maternal as well as neonatal morbidity and mortality. A comprehensive management approach is needed for evaluation and management of these patients. In our study the incidence of cardiac diseases amongst pregnant patients was found to be $0.58 \%$. Kosuru et al conducted a study to evaluate the influence of biological factors in Maternal and Perinatal Outcome in Heart Disease Complicating Pregnancy. ${ }^{10}$ In this study amongst 25,345 deliveries taking place during study period total number of cases with heart diseases was 145 hence, the incidence of heart disease in this study was found to be $0.5 \%$ which was similar to our study. Some other authors such as Wasim et al (1\%) and Bangal et al (1.3\%) have reported a slightly higher incidence of heart diseases in pregnant women. ${ }^{11,12}$

The most common cardiac pathology seen in studied cases was found to be rheumatic heart diseases followed by congenital heart diseases, cardiomyopathy and arrythmias. 
Asghar et al conducted a study to assess the maternal and fetal outcome in pregnancies associated with maternal heart disease. The authors found that congenital heart disease (CHD) was present in $28 \%$ cases and $66 \%$ had Rheumatic Heart Disease (RHD) and mitral stenosis which was the dominant lesion. ${ }^{13}$ Similar findings were also seen in our study. In a similar study Indira et al also reported rheumatic valvular heart diseases to be most common type of cardiac diseases seen in studied cases. ${ }^{14}$

In our study majority of the patients $(76.19 \%)$ belonged to NYHA grade I whereas $8(19.05 \%)$ patients belonged to NYHA class II. 1 patient belonged to NYHA Class III and Class IV respectively. Isolated mitral stenosis secondary to rheumatic valvular involvement was the single most common lesion seen in studied cases. The other common valvular lesion was found to be isolated mitral regurgitation and Mixed valvular lesions The most common congenital heart disease was found to be small ventricular septal defect with no Pulmonary arterial hypertension. Kamat et al conducted a study to analyze cardiac diseases in pregnancy. The authors also found mitral stenosis to be the most common cardiac condition which was seen in $40.5 \%$ cases the other valvular involvement reported by the authors include mitral regurgitation and mixed valvular involvement. ${ }^{15}$ The findings of this study were similar to our study.

In our study atrial septal defect as well as ventricular septal defects were common congenital heart diseases seen in cases. Mehta conducted a study to analyze the profile of cardiac diseases in pregnancy and its associated complications. The authors found that most common congenital heart disease was atrial septal defect which was seen in 4 out of 6 cases. ${ }^{16}$ The authors such as Pujitha also reported Atrial septal defect to be the most common congenital heart disease complicating pregnancy. The other common congenital heart disease reported by this author was ventricular septal defect. ${ }^{17}$ These findings were similar to the findings of our study as ventricular septal defect and atrial septal defects were most common congenital heart diseases seen in our study also.

Amongst studied cases in $26(61.90 \%)$ patients normal vaginal delivery was done whereas emergency and elective LSCS was done in $9(21.43 \%)$ and 6 (14.29\%) patients respectively. Whether a planned cesarean section is beneficial for pregnant women with heart diseases has been a topic of immense interest and debate amongst obstetricians and many studies have differing conclusions on this topic. However, many large comparative studies have found that planned cesarean section is not beneficial for these patients and should be done in carefully selected cases. Ruys et al undertook a study to investigate the relationship between mode of delivery and pregnancy outcome in women with pre-existing heart disease. In this study caesarean section was planned in 393 cases out of which $172(44 \%)$ cesarean sections were planned for cardiac and 221 for obstetric indications. The authors found that in those delivered by elective or emergency caesarean section, there was no difference in maternal mortality, postpartum heart failure or hemorrhage. The authors found that gestational age (37 versus 38 weeks $\mathrm{p}=0.003)$ and birth weight $(3073$ versus $2870 \mathrm{~g} \mathrm{p}<0.001)$ were lower in women delivered by caesarean section compared with women delivered by vaginal delivery. The authors concluded that planned caesarean section does not confer any advantage over planned vaginal delivery, in terms of maternal outcome, but was associated with an adverse fetal outcome. ${ }^{18}$

In our study $4(9.52 \%)$ patients developed postpartum hemorrhage. Amongst remaining patients 7 (14.29\%) patients developed postpartum cardiac failure and required oxygen supplementation-existing heart diseases is known to be one of the risk factors for Postpartum hemorrhage. Cauldwell et al undertook a study to identify the factors associated with an increased post-partum blood loss in women with congenital heart disease. The authors found that the average volume of blood loss in women with CHD was twice that expected. The risk factors for increased chances of postpartum hemorrhage included women who had been on anticoagulants, had a forceps delivery, emergency Caesarean section or general anaesthesia. ${ }^{19}$

Finally, analysis of perinatal outcome in women with cardiac diseases in our study showed that low birth weight $(23.81 \%)$ followed by birth asphyxia $(19.05 \%)$. Transient tachypnea of newborn and respiratory distress were common morbidities seen in neonates. Many of these pathologies are basically due to intrauterine growth restriction as well as due to preterm delivery. In our study $61.90 \%$ neonates were found to be low birth weight (less than $2.5 \mathrm{~kg}$ ). The cause of this low birth weight was intrauterine growth restriction and premature delivery or a combination of both. Abdel-Hady ES conducted a study to assess the maternal and perinatal outcome of pregnancies complicated by cardiac disease. The authors found that Birth weight of babies born to mothers with cardiac diseases were significantly lower than those of control group. 20 The findings were similar to our study.

We didn't study the compounding factors which might have affected the perinatal outcome such as factors causing intrauterine growth restriction or birth asphyxia and respiratory distress in newborn which might be having some specific etiology. But such a detailed analysis of neonatal factors was beyond scope of this study and this was limitation of our study.

\section{CONCLUSION}

Cardiac conditions in pregnant women are an important cause of maternal as well perinatal morbidity and mortality and require a comprehensive management strategy involving physicians, cardiologists and obstetricians. An early diagnosis (preferably before conception) and management during pregnancy is essential to reduce maternal as well as perinatal outcome in these cases. 
Funding: No funding sources

Conflict of interest: None declared

Ethical approval: The study was approved by the Institutional Ethics Committee

\section{REFERENCES}

1. Ashrafi R, Curtis SL. Heart Disease and Pregnancy. Cardiol Ther. 2017;6(2):157-73.

2. American College of Obstetricians and Gynecologists' Presidential Task Force on Pregnancy and Heart Disease and Committee on Practice Bulletins-Obstetrics. ACOG Practice Bulletin No. 212: Pregnancy and Heart Disease. Obstet Gynecol. 2019;133(5):e320-56.

3. Avila WS, Ribeiro VM, Rossi EG. Pregnancy in Women with Complex Congenital Heart Disease. A Constant Challenge. Arq Bras Cardiol. 2019;113(6):1062-9.

4. Pieper PG. Expected and unexpected cardiac problems during pregnancy. Neth Heart J. 2008;16(12):403-5.

5. Aka N, Arpacı S, Vural F, Köse G. Perinatal and neonatal outcomes of maternal heart diseases. Clin Exp Obstet Gynecol. 2016;43(4):560-4.

6. Fernandes SM, Arendt KW, Landzberg MJ, Economy KE, Khairy P. Pregnant women with congenital heart disease: cardiac, anesthetic and obstetrical implications. Expert Rev Cardiovasc Ther. 2010;8(3):439-48.

7. Adam K. Pregnancy in Women with Cardiovascular Diseases. Methodist Debakey Cardiovasc J. 2017;13(4):209-15.

8. Koutrolou-Sotiropoulou P, Parikh PB, Miller C, Lima FV, Butler J, Stergiopoulos K. Impact of Heart Disease on Maternal and Fetal Outcomes in Pregnant Women. Am J Cardiol. 2015;116(3):474-80.

9. Parsonage WA, Zentner D, Lust K, Kane SC, Sullivan EA. Heart Disease and Pregnancy: The Need for a Twenty-First Century Approach to Care. Heart Lung Circ. 2021;30(1):45-51.

10. Kosuru LK, Kumari A. Clinical study of maternal and perinatal outcome in heart disease complicating pregnancy at tertiary referral center of Telangana State. MedPulse - International Journal of Gynaecology. 2018;8(2):46-54.

11. Wasim T, Amer W, Majrroh A, Siddiq S. Foetomaternal outcome of pregnancy with cardiac disease. J Pak Med Assoc. 2008;58(4):175-8.

12. B Bangal V. Clinical Study of Heart Disease Complicating Pregnancy. IOSR Journal of Pharmacy (IOSRPHR). 2012;2(4):25-8.

13. Asghar F, Kokab H. Evaluation and outcome of pregnancy complicated by heart disease. J Pak Med Assoc. 2005;55(10):416-9.

14. Indira, Sunitha K, Jyothi. Study of Pregnancy Outcome in Maternal Heart Disease IOSR Journal of Dental and Medical Sciences. 2015;7(2):06-10.

15. Kamat AV, Dama S. Clinical study of cardiac diseases during pregnancy. Int $\mathrm{J}$ Reprod Contracept Obstet Gynecol 2016;5:855-9.

16. Mehta LR, Shah J. Cardiac diseases in pregnancy: clinical profile and fetomaternal complications. Int $\mathbf{J}$ Reprod Contracept Obstet Gynecol. 2017;6:4934-7.

17. Pujitha KS, Sheela SR, Jyothi NS. A study of maternal and fetal outcome in cardiac disease in pregnancy at tertiary care center. Int J Reprod Contracept Obstet Gynecol. 2017;6:5095-8.

18. Ruys TP, Roos-Hesselink JW, Pijuan-Domènech A, Vasario E, Gaisin IR, Iung B et al. ROPAC investigators. Is a planned caesarean section in women with cardiac disease beneficial? Heart. 2015;101(7):530-6.

19. Cauldwell M, Von Klemperer K, Uebing A, Swan L, Steer PJ, Gatzoulis M et al. Why is post-partum haemorrhage more common in women with congenital heart disease? Int J Cardiol. 2016;218:28590.

20. Abdel-Hady ES, El-Shamy M, El-Rifai AA, Goda H, Abdel-Samad A, Moussa S. Maternal and perinatal outcome of pregnancies complicated by cardiac disease. Int J Gynaecol Obstet. 2005;90(1):21-5.

Cite this article as: Kumar T, Tandi R, Thalla A. Maternal and perinatal outcome in heart disease complicating pregnancy. Int J Reprod Contracept Obstet Gynecol 2021;10:3725-31. 